Res Mobilis Revista internacional de investigación en mobiliario

y objetos decorativos

Vol. 7, nº. 8, 2018

\title{
EL MOBILIARIO DE SACRISTÍA DE LA S. I. CATEDRAL DE ORIHUELA: EL ESCULTOR JOSÉ GANGA RIPOLL VESTRY FURNITURE OF THE ORIHUELA CATHEDRAL. THE SCULPTOR JOSÉ GANGA RIPOLL
}

\author{
Mariano Cecilia Espinosa* \\ Gemma Ruiz Ángel \\ Universidad de Murcia \\ Museo de Arte Sacro de Orihuela
}

\section{Resumen}

El mobiliario de la sacristía de la Catedral de Orihuela, en este caso encuadrado en el Barroco, denota la relevancia que se dio a estos espacios auxiliares de los templos, y a sus propios muebles que tenían unas funciones muy específicas: la conservación adecuada de los ornamentos litúrgicos, y su carácter artístico para reforzar la belleza de la propia arquitectura donde se insertaba. Para ello, se confiaba su elaboración a artistas de primer grado como es el caso de José Ganga Ripoll, reputado escultor y retablista del setecientos, colaborador en diversos trabajos del maestro de mayor relevancia en el Sureste, Francisco Salzillo. Nuestra aportación no se limita exclusivamente al análisis de la obra en sí misma, sino que documentamos el origen familiar de su artífice para completar una biografía esbozada por Gómez Moreno y otros autores, así como su posible formación junto al tallista Juan Bautista Borja, aspecto que evidencia la propia talla de la cajonera catedralicia.

Palabras clave: Catedrales, Orihuela, barroco, sacristías, mobiliario.

\begin{abstract}
The furniture of the sacristy of the cathedral of Orihuela, Baroque style, shows the relevance to the auxiliary spaces of the temples, and their furniture that had very specific functions: the preservation of liturgical ornaments and their artistic character to reinforce the beauty of the architecture itself. To this end, it was entrusted to artists of the first degree, such as José Ganga Ripoll, famous sculptor and retablist of the seven hundred, collaborator in several works of the most important sculptor in the Southeast, Francisco Salzillo. Our
\end{abstract}

\footnotetext{
*E-mail: mariano.cecilia@um.es, gemma@museodeartesacro.es
} 
contribution is not limited exclusively to the analysis of the work itself, but we document the origin of the author's family to complete a biography outlined by Gómez Moreno and other authors, as well as his possible formation with the carver Juan Bautista Borja, aspect that shows the size of the cathedral drawer itself.

Keywords: Cathedrals, Orihuela, baroque, sacristies, furniture.

\section{Introducción}

En este trabajo planteamos el estudio de un mobiliario destinado a espacios arquitectónicos singulares, la sacristía de las iglesias católicas, en este caso a la de mayor estatus, -la Catedral-, y con unas funciones muy específicas delimitadas por la liturgia y el embellecimiento interior del templo. La conservación es su principal función dado que debían guardar adecuadamente, y de forma ordenada, los ornamentos textiles destinados al servicio litúrgico, cuyos colores variaban de acuerdo al tiempo de la liturgia y sus tipologías dependían de cuándo y quien los llevaba. Para ello, era imprescindible el orden, de ahí la existencia de distintos cajones distribuidos por toda la estancia, siempre en los laterales, para mantener un espacio diáfano, ya que en la propia sacristía se desarrollaban algunos actos ceremoniales como la veneración de reliquias, o la salida de procesiones claustrales. En este sentido, durante el Barroco, las sacristías dejan de ser meros contenedores de ajuares y se transforman en espacios de relevancia, incluso de cierta monumentalidad, a los que se le dota de elementos artísticos dignos de su rango catedralicio. A pesar de ser un sitio reservado para los sacerdotes y demás ministros, su importancia se amplía al ser el lugar donde se reunían los participantes en el culto católico antes y después de los oficios divinos, pues desde allí partían las procesiones hacia el altar mayor ${ }^{1}$.

La complejidad y la magnificencia que adquirió la liturgia en la Edad Moderna, y en consecuencia, el aumento de los vasos sagrados y ornamentos, propició la necesidad de crear espacios de mayor amplitud, en los que poder albergar numerosos cajones y armarios para guardar y conservar, del modo adecuado, toda esa gran variedad de objetos, muchos de ellos preciosos ${ }^{2}$, que además se iban incrementando continuamente, tal como se puede apreciar en las visitas pastorales ${ }^{3}$ donde se recogen los inventarios de piezas existentes en ellas. Este mobiliario fue ricamente labrado, de acuerdo a la estancia donde se ubicaba, y al carácter sagrado de la sacristía, así como a las propias disposiciones tanto de los prelados, como se observa en los mandatos de las distintas visitas pastorales de los obispos -o del Cabildo Catedralicio en caso de sede vacante-, y en los informes de las diócesis que se remitían al Vaticano, donde se prestaba especial atención al cumplimiento de las disposiciones tridentinas ${ }^{4}$.

Por tanto, en la construcción de estos espacios en las catedrales y templos católicos no sólo intervinieron arquitectos, sino escultores y tallistas de renombre, que dotaron a las iglesias de elementos artísticos de primer orden, 
significativamente de mobiliario, un aspecto no suficientemente estudiado en la historia del arte, y en particular en el Barroco español.

\section{La cajonería de la Catedral de Orihuela}

Como señala Del Baño Martínez ${ }^{5}$, la sacristía de la Catedral de Orihuela es uno de los pocos ejemplos de planta octogonal que se pueden encontrar en España. Su diseño puede estar influenciado por la sacristía renacentista de la iglesia de Santiago ${ }^{6}$, otra de las parroquias históricas de la ciudad, o relacionada simbólicamente con la idea de salvación. Sea cual fuere la motivación de su diseño, se lograba ampliar el conjunto catedralicio con esta estancia y otras anejas, como la capilla de la Comunión y el aula capitular, que servían para paliar en cierta medida los problemas espaciales que endémicamente tenía la Catedral desde hacía siglos.

Tras finalizar su construcción 7 , se acometió la dotación del mobiliario necesario para completar la obra, una cajonera para albergar y custodiar el ajuar litúrgico, con el fin de conservar adecuadamente las piezas textiles de gran calidad que por entonces existían, y en la mayoría de los casos aún se conservan procedentes de la Catedral oriolana en el Museo Diocesano de Arte Sacro. Asimismo, se ornamentaba el nuevo espacio ganado con mobiliario de calidad acorde con su relevancia. El proyecto se abordó desde la junta parroquial como era preceptivo en el caso de la administración de fondos destinados a la fábrica del templo.

Las primeras noticias sobre el proceso de ejecución del nuevo mobiliario se remontan al 21 de diciembre de 1730 cuando la junta de parroquia acordó hacer unos cajones nuevos para la sacristía, ya que había mucha ropa litúrgica y no había sitio suficiente para guardarla, nombrando a Francisco Ximénez, con intervención del sacristán mayor Gregorio Oliva, para que se redactaran los capítulos necesarios y se realizaran los nuevos cajones ${ }^{8}$. En este sentido, es interesante la presencia del sacristán mayor entre los comisarios de la obra, pues pone de manifiesto la necesidad de su presencia por el carácter no sólo artístico sino funcional del mueble.

En la junta de parroquia del 24 de junio de 1731 se insistió de nuevo en la necesidad de redactar los capítulos de la obra, en virtud del acuerdo anterior, instando para ello al comisario Francisco Ximénez y al sacristán mayor. El 18 de noviembre del mismo año, el citado sacristán de la Catedral presentó tres diseños de los cajones que se pretendían realizar para la sacristía. La junta parroquial acordó que se ejecutaran según el mejor diseño de los tres presentados, admitiendo otros si se hicieran por nuevos artífices interesados en realizar dicha obra. Se determinó que para poder ejecutar la cajonería con la mayor brevedad y perfección se nombrara un nuevo comisario, en este caso Joseph Juan Vigo y Miravete, canónigo penitenciario de la Santa Iglesia Catedral y se mantuviera a Francisco Ximénez, catedrático de leyes de la Universidad de Orihuela, regidor 
por su Majestad, para formar los capítulos necesarios y establecer el remate correspondiente, otorgando toda libertad y confianza a los susodichos electos ${ }^{9}$.

El 28 de abril de 1732 se remató el mobiliario bajo los capítulos previamente concertados por los comisarios de la obra. En el citado remate presentaron sus posturas el tallista y escultor Antonio Perales ${ }^{10}$ quien rebajó la cantidad prevista inicialmente, en 100 libras y 16 dineros, con la condición de que recibida la fianza se le debía de pagar la mitad del dinero y la restante al concluir la obra. Por su parte, Joseph Ganga, maestro de escultura, vecino de la ciudad de Murcia, rebajó algo más el precio de salida, concretamente 80 libras y 21 dineros, con la condición de recibir de entrada 200 libras. Pocas semanas después, el 15 de mayo, los comisarios explicaron que se habían practicado todas las diligencias indispensables para el mayor beneficio de la parroquia en el remate que se había producido semanas antes, en el día 28 de abril, en favor de Joseph Ganga, bajo el precio de 946 libras, 12 sueldos y 2 dineros. De entrada se abonarían 200 libras después de otorgar la correspondiente escritura de obligación y fianzas, a la mitad de los trabajos se entregarían 373 libras, 6 sueldos y 1 dinero y las restantes cantidades estando recibida y concluida la obra de acuerdo a los diseños y capítulos estipulados en el remate ${ }^{11}$.

En esta misma junta se presentó el memorial de Joseph Ganga con las fianzas que proponía, siendo sus fiadores Pedro Thomas, Pedro García, Jaime Martínez y Félix Ferrando, vecinos todos de la ciudad de Orihuela. Las citadas fianzas fueron aprobadas por mayoría de votos en la junta parroquial, acordando entregar las cantidades acordadas al maestro escultor en los plazos y tiempos previstos. Ese mismo día, Ganga se había obligado a realizar la obra ante el notario Julián Risueño, bajo la cantidad antedicha y los capítulos y diseños realizados para el efecto ${ }^{12}$. Las capitulaciones, recogidas en los archivos de las casas de ayuntamiento, determinaban que la obra se realizaría en el tiempo de un año a partir del remate de la cajonería, con la condición de que el maestro tendría que pagar de su costa los salarios de remate y obligación, así como 20 libras por los trabajos de los diseños ${ }^{13}$ y formación de los citados capítulos ${ }^{14}$.

En la junta de parroquia del 30 de noviembre de 1732, se expuso un memorial presentado por Joseph Ganga, referido en esta ocasión como tallista, en donde exponía que de acuerdo al remate del mueble de sacristía que estaba trabajando solo se le había entregado el primer plazo de las pagas, es decir 200 libras, que había empleado para comprar la mayor parte de la madera y prácticamente toda estaba labrada para dicho fin. En el memorial, solicitaba un adelanto de 100 libras a cuenta de la segunda paga para cubrir los gastos de la madera que necesitaba para concluir la obra y la manutención de siete oficiales que estaban trabajando bajo sus directrices. En vista de estas razones, los parroquianos acordaron que Ginés Martínez, maestro carpintero ${ }^{15}$, presente en la citada junta, reconociese la obra y si la visura estuviese en orden a los capítulos se le otorgara la correspondiente carta de pago.

El 15 de marzo de 1733, se reunió de nuevo la junta parroquial con motivo de estudiar el memorial presentado por Joseph Ganga ${ }^{16}$, para que se le otorgara la segunda paga del mobiliario, ya que podía colocar en ese momento más de la 
mitad de la obra. En dicho memorial confirmaba que se le habían entregado 300 libras con cuya cantidad había formado un cuerpo del mueble en la sacristía de la iglesia. Esto indica que en estas fechas ya se había instalado una tercera parte de la cajonería en el lugar que debía ocupar. Sin embargo, en su relación exponía que necesitaba más dinero para comprar madera de nogal y de esta manera poder concluir más de dos partes de las tres de dicha obra que faltaban por ejecutar. Por otro lado, Joseph Ganga presentó el gasto de hierro y bronce que tenía que utilizar en la cajonera para los aldabones y mascarones de los cajones del mueble. El maestro solicitó a los parroquianos que de las 646 libras que quedaban por entregarle se le librasen 446 libras para continuar sus trabajos, comprar el hierro, bronce y la madera, así como para pagar a sus oficiales, y que las restantes 200 libras se le abonarían a la conclusión de la cajonería ${ }^{17}$.

La junta parroquial deseando que se continuara con la mayor brevedad la expresada obra y que se colocara en el sitio de su destino, determinó que Ginés Martínez, maestro carpintero, reconociese los muebles que estaban ejecutados en la mencionada sacristía y aquellos que estaban en casa del escultor, a fin de establecer el estado de adelanto en el que se encontraban los trabajos, y así entregar la cantidad requerida por el demandante, siempre que valiesen lo estipulado. Unos meses después, el 24 de junio, se expuso a la junta que a pesar de tener colocada buena parte del mobiliario en la sacristía, Joseph Ganga había incumplido los términos estipulados en los capítulos ya que se había terminado ese día el término para entregarla acabada. La junta resolvió que se le notificara al maestro que de no entregar la obra con la mayor brevedad posible la parroquia actuaría en consideración ${ }^{18}$.

El 15 de noviembre de 1733, Francisco Ximénez, comisario electo para la obra de la cajonería catedralicia, expuso a la junta que Joseph Ganga Ripoll no había concluido hasta la fecha el mobiliario que se le había encargado, habiendo sobrepasado notablemente el tiempo estipulado, a pesar de las múltiples diligencias extrajudiciales que se habían realizado. Ante esta situación, la junta acordó que se librara por el escribano una copia de la escritura de obligación otorgada por el maestro escultor y sus fiadores para entablar acciones judiciales contra el obligado dando poder para ello a Pascual Sánchez ${ }^{19}$.

Sobre este asunto no se vuelve a hablar hasta unos meses después dónde todo parece estar ya solucionado. En la junta parroquial celebrada el 7 de marzo de 1734 se leyó el memorial presentado por Joseph Ganga ${ }^{20}$, en donde informaba que había concluido la obra de la cajonería que debía haber terminado en abril de 1733 por el trabajo de más que había realizado, cuyo coste ascendía a 600 libras. Con el fin de determinar estos excesos realizados en la obra y valorar los trabajos de Ganga Ripoll, se dispuso que los electos Juan Vigo y Francisco Ximénez nombrasen expertos que dictaminaran si el mueble de sacristía se encontraba dentro de lo estipulado en los capítulos y si era necesario otorgar una remuneración por los trabajos de mejora que según el autor había realizado en el citado mobiliario ${ }^{21}$.

En la junta del 20 de marzo de 1734 los comisarios expusieron que tras haber leído las declaraciones de los expertos nombrados para la visura de la 
cajonera realizada por José Ganga, se encontraba dentro de lo acordado en los capítulos que se realizaron para tal efecto. En la relación de los peritos se exponían las mejoras realizadas en el conjunto mueble, ante esto los comisarios declararon que era necesario que se declarasen ante el Real Justicia de la Ciudad, y si estas mejoras eran necesarias y útiles se pagaran al maestro escultor. En este sentido, señalaban que del precio estipulado había que rebajar el importe de la escalerilla y nicho de la obra, que era de pino, así como los aldabones y máscaras que se encontraban en los capítulos, ya que se habían encargado a otros maestros. El reconocimiento lo realizó el también escultor y tallista Jacinto Perales en donde declaraba estar bien hecha la obra, mientras el exceso que había realizado en ella ascendía a 119 libras con 10 sueldos ${ }^{22}$. Finalmente, el 2 de abril de 1734 se otorgó la correspondiente carta de pago por el último plazo convenido en el remate y la cantidad que Jacinto Perales había determinado en su reconocimiento ${ }^{23}$.

De los documentos parroquiales anteriormente expuestos podemos extraer, además de las vicisitudes particulares del encargo, varias conclusiones de relevancia: la condición de Joseph Ganga como maestro de escultura, lo que denota en aquellos momentos su maestría en estas artes, su reconocimiento social y profesional, así como la amplitud del taller que tenía a su cargo, donde trabajaban siete oficiales, por lo que estaríamos ante un escultor afianzado en la ciudad de Murcia, capaz de ejecutar grandes empresas como veremos en el siguiente apartado. Por otra parte, Ganga incluyó importantes mejoras en el proyecto inicialmente previsto, al igual que haría años después en el retablo mayor del Convento de Santa Ana de las madres dominicas de Murcia, algo habitual en los artistas del momento, cuyos "excesos" vienen dados siempre por la creatividad y el deseo de realizar obras que pudieran sobrepasar los trabajos de sus contemporáneos, en una coyuntura donde la competitividad era máxima en el campo de la retablística y la escultura ${ }^{24}$. En el caso de las mejoras introducidas en la cajonera catedralicia fueron valoradas positivamente con el informe de otro gran tallista, Jacinto Perales, y con la connivencia de los canónigos oriolanos que evidentemente seguirían el proceso constructivo y verían como Ganga se alejaba del diseño inicial, que no le pertenecía, permitiendo sucintamente la ejecución libre de la obra por parte del escultor oriolano.

\section{El tallista y escultor Joseph Ganga Ripoll}

Como hemos podido comprobar, el encargo de la cajonera se realizó al tallista y escultor oriolano, Joseph Ganga Ripoll, que en ese momento tenía su taller en Murcia, donde en consecuencia también residía. Como bien apuntó Gómez Moreno ${ }^{25}$, y posteriormente Concepción de la Peña Velasco ${ }^{26}$, este destacado escultor y tallista era oriundo de la ciudad de Orihuela. Esta afirmación se ha podido evidenciar documentalmente tras localizar su partida de bautismo en el archivo parroquial del Salvador. Por tanto, hoy tenemos la certeza que nació y fue bautizado en Orihuela el 27 de enero de 1697, hijo de Juan Ganga Bellod, natural de Biar en el reino de Valencia, y de Justa Ripoll, oriunda de 
Villena $^{27}$. Su padre, Juan Ganga, hijo de Francisco Ganga y de Esperanza Bellot se casó en 1676 con Jusepa Parra en la parroquia de las Santas Justa y Rufina de Orihuela ${ }^{28}$, era carpintero en la ciudad, según hemos documentado en tres ápocas que el Cabildo Catedralicio abonó a cuenta de diversos trabajos, todos ellos de carpintería menor ${ }^{29}$. También se tiene constancia de encargos destinados a la capilla de la Soledad del fosar de la Catedral, pero siempre realizando obras de poca envergadura ${ }^{30}$.

Como señalan los documentos, el oficio le venía a José Ganga de su padre aunque la calidad artística que alcanzaron sus obras implican su formación en un taller de relevancia, muy posiblemente el del escultor Juan Bautista Borja, autor entre otras obras de la sillería del coro catedralicio, ejecutada entre 1717 y 1718, una obra donde algunos autores apuntan la participación de un joven Francisco Salzillo $^{31}$. Este dato es relevante, pues en el momento de la realización del coro, José Ganga se encuentra en Orihuela y vinculado a la parroquia del Salvador -la S. I. Catedral de Orihuela-, tal como demuestra su casamiento el 19 de octubre de 1718 en la Catedral con Florentina Santa Cruz, natural de Aspe, en cuya partida matrimonial se le cita como "natural y vecino de esta ciudad32".

La obra de José Ganga, significativamente sus retablos, pone de manifiesto su calidad como artista lo que le llevó a trabajar conjuntamente con el escultor murciano Francisco Salzillo Alcaraz, sin duda uno de los grandes escultores del siglo XVIII en España. En este sentido, González Moreno lo calificó como "genial tracista y ejecutor de retablos ${ }^{33}$ ". Su obra, evidencia el alto nivel alcanzado en la escuela interregional forjada en el setecientos entre Murcia y Orihuela, donde los retablistas y escultores oriolanos alcanzaron un nivel de calidad artística muy alto que les permitió afrontar trabajos de envergadura en un momento de gran demanda por parte del estamento eclesiástico. Son conocidas y valoradas sus obras en el campo de la retablística conservadas en la ciudad de Murcia, como el retablo de santa Ana del monasterio de las Anas, realizado en colaboración con Salzillo, o el baldaquino de Santa Clara la Real de Murcia (1754) una de las obras que muestra su verdadero talento como diseñador y tallista ${ }^{34}$, y otras en poblaciones como Lorca ${ }^{35}$ o Huercal Overa (Almería). No obstante, son bastante desconocidos trabajos como el que analizamos en este artículo, y que demuestra su valía como tallista para encargos de la relevancia de una Catedral.

\subsection{El diseño de la cajonada}

La conservación del mueble de la sacristía de la Catedral de Orihuela nos permite estudiar el diseño y la ejecución de Ganga Ripoll en este interesante mueble litúrgico. El mobiliario se adapta perfectamente a cada uno de los lados de la planta octogonal de la sacristía, con lo que al igual que su homóloga de la iglesia de Santiago, se consigue ganar en espaciosidad. En su diseño destacan las cuatro puertas de arcos de medio punto distribuidas simétricamente en el conjunto y un gran armario central con tres gradas destinado para albergar las santas reliquias de la Catedral que preside tanto el conjunto mobiliar como la 
estancia. Este último mueble fue ampliamente reformado tras la conclusión de la cajonera como veremos en adelante.

En los capítulos se ponía especial énfasis en “... aser la talla según buen artífice y como muestran los diseños ${ }^{36}$ ". El autor de la traza no debió ser José Ganga, ya que en el capítulo 21 de la obra se especificaba que el maestro al que se le rematase la cajonería debería pagar los trabajos de los diseños y la formación de los capítulos. Desconocemos quién pudo realizar las trazas, aunque los repertorios ornamentales utilizados en la talla de la cajonería están relacionados con los trabajos del escultor Juan Bautista Borja dada las afinidades estilísticas que aparecen en la misma. No obstante, ya hemos comentado que las mejoras introducidas por Ganga nos revelan una importante modificación al respecto del modelo capitulado y rematado a su favor, por lo que es imposible definir con claridad cómo era el diseño original.

Como bien señaló Joaquín Sáez Vidalin, en la obra se aprecian rasgos inequívocos de la influencia del estilo de Juan Bautista Borja, la presencia de máscaras muy expresivas, las cartelas de curva y contra curva o las inflexiones inspiradas en rocallas, son un buen ejemplo de la adopción de elementos característicos de los repertorios iconográficos del artista valenciano, presentes en obras tan cercanas como la sillería del coro de la Catedral de Orihuela realizada en 1717 por Borja y Tomás Llorens, o en la portada principal del actual Palacio del Barón de la Linde en la misma ciudad ${ }^{38}$.

La comparación del trabajo de talla realizado en el coro catedralicio con el de la cajonería muestra que en la sillería coral los paneles historiados con escenas de la biblia apócrifa de Lyon son de una ejecución más pobre que los cuarteles decorativos existentes en todo el conjunto, donde se observa una altísima calidad, -fruto sin duda de la intervención de dos autores Tomás Llorens y Juan Bautista Borja-, así como los ángeles niño que jalonan la parte superior del conjunto, cuya excelencia supera al resto del conjunto. En este sentido, la parte decorativa del coro es la que nos permite establecer paralelismos y comparaciones con el mueble de sacristía de Ganga que presenta repertorios ornamentales muy similares. Sí que se observa con claridad una mayor delicadeza en las decoraciones del coro, trabajadas con mayor soltura y maestría, frente a la talla del taller de Ganga que presenta una calidad notable pero mayor dureza y rigidez en las formas, siguiendo esa idea de simetría y orden que presenta todo el diseño ornamental y estructural del mueble de sacristía.

La disposición general del conjunto se articula en torno a dos cuerpos: los muebles con cajones para albergar principalmente los ornamentos textiles litúrgicos y un paneleado superior con pilastras talladas con formas inspiradas en rocallas, -que no llegan nunca a serlo-, decoradas con motivos flores y vegetales, que a menudo se conjugan con el jarrón de azucenas, emblema del Cabildo Catedralicio, ménsulas a modo de capiteles, entablamentos curvados, cornisas, y cresterías formadas por cartelones y veneras entrelazadas en un juego de formas, que podríamos determinar cómo proto rocallas, dispuestas a lo largo de todo el mueble. En este sentido, en los capítulos de la cajonería se especificaba algunos detalles del diseño y de la talla que se debía realizar. En el último caso, los 
adornos de los escudos del remate del mueble cuyo grosor debía tener el relieve de "medio tablón del marco de torno", los jarros de azucenas que debían de ser de medio relieve o el adorno de las tallas de las pilastras cuyo relieve sería el del grueso de la pilastra y la talla de su remate sería “... un cartelón de relieve en forma de capitel como se demuestra por los diseños ${ }^{39}$ ". Como podemos observar, en principio Ganga sigue esencialmente los elementos básicos estipulados aunque con su propia interpretación tal como hemos descrito en referencia al resultado final del trabajo.

Mientras, en las esquinas localizamos cuatro puertas de arco de medio punto, decoradas con cuarterones ricamente ornamentados con un motivo predominante la jarra de azucenas, y otros de carácter exclusivamente decorativo como cartelones, formas de curva y contra curva, además de trazos vegetales y geométricos. Estos vanos son aparentes pues en algunos casos tienen distintas funcionalidades: aquellas que están situadas en el lado que preside la estancia dan acceso al vestidor de los canónigos y dependencias auxiliares, mientras las otras dos tienen otros usos, una de ellas como armario, y la restante como acceso a una escalera que comunicaba con habitáculos superiores destinados en aquel momento a albergar el archivo histórico de la Catedral.

\subsection{Los materiales}

Según queda estipulado en los capítulos de la cajonería, los materiales utilizados dependerían de la función que desempeñaría la madera en la obra. Para el armazón, tarimas y suelos de los tres nichos se realizarían en madera sargaleña seca ${ }^{40}$ y de buena calidad. Este tipo de maderaje era utilizado para la construcción de aparatos arquitectónicos como retablos, sin duda era el material idóneo y comúnmente utilizado para levantar estructuras de madera, por tanto no es de extrañar su utilización en el armazón del mueble de sacristía de la Catedral.

Mientras para los frontales de los cajones, armazón y pilares, cornisas, armarios, adornos del coronamiento de la cajonería y puertas de los nichos se emplearía la madera de nogal de buena calidad, seca y procedente de la localidad alicantina de Biar. Asimismo, para el armario de las reliquias se especificaba la utilización del nogal así como para los alzados situados encima del mueble. La talla tenía que ser bruñida con piedra de dorador y las partes sin tallas, lisas o planas debían de ser tratadas con esparto y cera, para su buen acabado y terminación ${ }^{41}$.

3.3. Los aldabones y herrajes de la cajonería; los plateros Bernardo Gil y Vicente Ycast

En el remate se especificaba que el maestro a cuyo cargo quedaría la dirección de la obra tendría la obligación de poner a su costa todo el herraje que fuera necesario para los cajones, realizando las piezas en hierro, así como la 
colocación de un mascarón de bronce en cada cajón del mueble. Sin embargo, y a pesar de estar contemplado en los capítulos, la junta de parroquianos acordó el 24 de junio de 1733 que los aldabones de la cajonería se realizaran en bronce sobredorado y no en hierro. Para este fin, se presentó un diseño para elaborar las citadas piezas a imitación de una muestra llevada a la junta, dando comisión a Joseph Juan Vigo, canónigo de la Catedral, para elegir al mejor artífice ${ }^{42}$.

Casi un año después, en la junta parroquial correspondiente al 17 de junio de 1734 se expuso que ante la hermosura de la obra que había hecho Ganga Ripoll, los modelos de aldabones expresados en los capítulos no estaban en consonancia con la cajonería que se había ejecutado. Con este fin, se determinó en juntas anteriores que se realizaran unos aldabones de bronce, y para ello los comisarios decidieron que se encargaran a Bernardo Gil, maestro platero de Orihuela ${ }^{43}$, a quién naturalmente también se le encomendaron los mascarones. El platero oriolano cobró 1 libra, 1 sueldo y 6 dineros por cada uno de los 48 aldabones y máscaras que había realizado, ascendiendo el total a 51 libras y 12 sueldos que, como era costumbre se le entregaron por el fabriquero. En la misma junta, se informó que habían mandado a José Sans Cesario, de oficio carretero, a la ciudad de Valencia para llevar a dorar los aldabones, mascarones y planchas que se debían fijar en la nueva cajonera de la sacristía, por lo que cobró 3 libras. En total ambas partidas habían costado a la parroquia 54 libras y 12 sueldos. El dorado corrió a cargo del platero valenciano Vicente Ycast, cuya carta de pago se había otorgado ante el escribano Ignacio Pérez, con un coste que ascendió a 89 libras, 13 sueldos y 8 dineros ${ }^{44}$.

A cada cajón se le colocaron dos aldabones, cada uno situado en un extremo, con planchas decoradas mediante el empleo de motivos vegetales y una palmeta central, mientras en el centro, donde se insertaba la llave, se instalaron mascarones diseñados en consonancia con los existentes en la talla de la cajonería, muy expresivos, con la boca profusamente abierta, y ornamentados a ambos lados con rocallas. Tal como pretendía la junta de parroquia, los frontales de cada uno de los cajones se enriquecieron desde el punto de vista decorativo con los mascarones y aldabas dorados que completaban un conjunto austero limitado a pequeñas muestras decorativas de carácter vegetal situadas en las esquinas de los cajones.

\section{El armario de las reliquias}

El conjunto de la cajonera lo preside un monumental armario donde se conservan las reliquias de la Catedral. Este mueble formó parte del proyecto encargado a José Ganga Ripoll, aunque fue enriquecido en años sucesivos por el escultor Jacinto Perales, de acuerdo al interés y a la iniciativa de los capitulares oriolanos que se mostraban muy activos, no sólo en la materialización del encargo, sino en definir bien el proyecto de acuerdo a sus gustos y preferencias. Como veremos a continuación, este armario está determinado por la presencia de la reliquia de mayor relevancia, el Lignum Crucis, una cruz - relicario gótico con dos astillas del sagrado madero. 
En este sentido, en la junta parroquial del 17 de abril de 1735 se expuso que era necesario y conveniente el adorno del armario destinado en la sacristía para las sagradas reliquias ${ }^{45}$ así como su mejor y decente colocación para poder celebrar en ella la función de la Vera Cruz, -con el Lignum Crucis-, en la Semana de Pasión y Semana Santa sin que se tuviera que solicitar prestados plata y alhajas para el referido adorno como en años atrás. Por la premura de tiempo y la urgencia por solventar la situación se determinó, sin ser aprobado por la junta de parroquia, que se hicieran los trabajos necesarios para conseguir el máximo esplendor en las funciones de Cuaresma y Semana Santa ${ }^{46}$.

La intervención consistió en la ejecución de una hornacina abocinada que permitía presentar todo el relicario en un graderío, en cuyos escalones se situarían las sagradas reliquias. Los distintos arcos están enmarcados y decorados por espejos y vidrios jalonados por cuarterones de talla dorados, cuyo diseño se remite a motivos vegetales y veneras, que varían en el arco interior donde se utilizan patrones basados en complejos conjuntos vegetales y cuarterones con cruces, aspecto muy significativo que está en relación con la presencia de la reliquia del Lignum Crucis. En este sentido, el conjunto tiene como fondo un lienzo reutilizado de la Virgen de la Soledad, devoción relacionada con la Vera Cruz, reliquia que a nuestro parecer presidiría todo el conjunto, tal como demuestra el interés de la parroquia por disponer del armario para las funciones pasionarias que tenían como protagonista el culto a la Cruz de Cristo. Toda la obra de ejecución de la talla, espejos y vidrios costó 65 libras, así como su dorado, que alcanzó el coste de otras 65 libras, más 3 libras por el dorado de los ángulos superiores del armario y parte de la pared que quedaba al descubierto ${ }^{47}$.

Pero la intervención del tallista Jacinto Perales no quedó ahí, se constatan los pagos de 2 libras y 18 sueldos por el gasto de madera de nogal para ampliar las puertas del armario en la parte superior al objeto de dotarle mayor monumentalidad: "para que se viera mejor y quedase mejor". Esta intervención, debe corresponder con el coronamiento del citado armario, formado por molduras curvilíneas decoradas en su interior, principalmente el espacio central, con flores, guirnaldas, cueros y formas arrocalladas, mientras, a modo de crestería, se sitúan elementos arquitectónicos arrocallados, y dos pelícanos en los extremos.

Ante la vistosidad y hermosura de la obra se determinó la necesidad de encarnar los rostros y cuellos de los relicarios como de dar a sus dorados nuevo esplendor, ya que el tiempo y la cera había deteriorado las encarnaciones. Por estos encargos se pagaron 9 libras por la encarnación y 10 libras y 10 sueldos por lustrar y limpiar el dorado antiguo, quedando "como recientemente hechas" 48 . Estos trabajos lo realizó el pintor de raigambre italiana José Poyo quién encarnó los siete medios cuerpos de los santos que allí se veneraban.

El resultado gustó mucho a la Ciudad que lo había contemplado en la función de la Vera Cruz. En total se solicitaba que se pagaran por el fabriquero las 155 libras que habían costado los trabajos, pero el canónigo Domingo Ruiz se opuso ya que según el Real Estatuto nueve de las fabricas determinaba que ninguna obra se hiciera sin preceder la determinación de la parroquia, y que dada la mayor suma de dinero que había costado, se debería haber subastado y 
rematado según los capítulos preceptivos, que no se habían redactado, por cuyos motivos se expuso que no se pagara la cantidad reservándose el derecho para hacer parte en el juicio de cuentas de dicha fabrica ${ }^{49}$.

El análisis comparativo entre los motivos y diseños decorativos de la talla de la cajonería realizada por Joseph Ganga y los empleados en los cuarterones de las puertas del armario de las reliquias denotan notables diferencias tanto en los esquemas formales como en los propios elementos ornamentales, significativamente en el uso de la rocalla como nuevo y distintivo recurso que, como es sabido, marca el nuevo estilo Rococó ${ }^{50}$. Todo parece indicar una intervención posterior relacionada con los trabajos realizados en el interior del armario, y puede estar ligada a la demanda en la junta parroquial del canónigo Ruiz que exponía que para la mayor perfección del armario se necesitaba que las puertas se abrieran de par en par lo que era preciso que se hiciera con el adorno que se requiere para la decencia del culto. Sobre esta proposición se nombró comisario para su ejecución a José Juan Vigo para que mandara hacer diseños y estableciera el coste que podrían tener las mejoras propuestas ${ }^{51}$.

Los cuarterones tallados en las puertas del armario de las reliquias nos remiten a un nuevo lenguaje, el Rococó, mucho más dinámico, donde se asume la rocalla como principal elemento decorativo, con el que se juega para formular nuevas formas decorativas, logrando una estética totalmente distinta a la empleada en la cajonera de Ganga.

\section{A modo de conclusión.}

Tras la recuperación de la ciudad después de los estragos de la Guerra de Sucesión, y en una coyuntura favorable, con estabilidad, ausencia de epidemias, consolidación económica y crecimiento poblacional, comienza una intensa actividad en las artes que afecta a la arquitectura con trabajos de mejoras y renovación arquitectónica o decorativa en las diferentes parroquias, iglesias, ermitas, palacios y edificios públicos que favorecieron la llegada de importantes artistas, principalmente del ámbito murciano, y la continuación de los talleres locales que desde finales del siglo XVII se estaban gestando en la ciudad para reanudar, en algunos casos, los programas constructivos iniciados tiempo atrás. En las parroquias oriolanas, esta renovación alcanzará al mobiliario de sus sacristías, en primera instancia con el mueble catedralicio, y seguidamente, con la cajonera de la nueva sacristía de la parroquia de las Santas Justa y Rufina, diseñada por Jaume Bort. A finales de siglo, en torno a 1780, se estrenará un nuevo mueble de tintes clasicistas en la sacristía renacentista de la parroquial de Santiago que venía a completar el conjunto de cajoneras en las tres iglesias parroquiales de la ciudad.

En este contexto de florecimiento artístico se desarrollan en la Catedral los trabajos de un escultor oriolano con un importante taller en Murcia: José Ganga Ripoll, colaborador en diversas obras del "escultor de mayor crédito de estos reinos", en palabras de sus contemporáneos, el murciano Francisco Salzillo. El proyecto ejecutado por Ganga en la sacristía catedralicia demuestra su 
consideración social y artística, su prestigio y buen hacer, capaz de dotar de monumentalidad a un nuevo espacio de la sede oriolana mediante la ejecución de un mobiliario de gran calidad donde es capaz de modificar el diseño original estipulado, un aspecto que demuestra su seguridad como maestro y la confianza en el resultado final de la obra, que es justipreciada positivamente por otros artistas, y aceptada por el propio Cabildo Catedralicio que pagara gustosamente a través de la junta de fábrica las mejoras realizadas en la talla de la cajonería.

El diseño ornamental realizado por Ganga en el mobiliario de sacristía viene a confirmar su relación con los trabajos del escultor Juan Bautista Borja con el que coincide en Orihuela cuando se está ejecutando la sillería coral, por lo que no sería descartable su participación en esta obra como miembro de su taller. Los motivos ornamentales empleados por Ganga siguen básicamente los propios de Borja en la sillería coral, aunque con diseños totalmente distintos, y una forma de tallar, ciertamente más rígida, que la talla suelta y fácil que se observa en los cuarterones decorativos del coro.

En el momento de realización y entrega del mueble se están produciendo cambios estilísticos de relevancia, como es la introducción de la rocalla en los repertorios ornamentales y, por tanto, la llegada del Rococó a estas tierras, tal como demuestran los repertorios decorativos tallados en los cuarterones del armario de las reliquias, una obra ejecutada inmediatamente después de la finalización de la cajonera o las incipientes rocallas presentes en los mascarones de bronce dorado del platero Bernardo Gil. No obstante, el escultor José Ganga, cuando entrega el conjunto mueble en 1734, aún no emplea plenamente este nuevo lenguaje que adoptará posteriormente en sus obras. Por lo tanto, este cambio estilístico queda muy bien documentado en el estudio que hemos realizado de este mobiliario que nos permite perfilar la llegada de la rocalla, y del Rococó al mediodía valenciano en torno a los años 1734 y 1735.

Como podemos comprobar el estudio del mobiliario, lejos de ser secundario, permite establecer procesos artísticos extrapolables al conjunto de las artes. En este trabajo hemos podido perfilar desde el punto de vista cronológico la llegada del Rococó a la ciudad de Orihuela, y por ende a su área de influencia geográfica, es decir la antigua Gobernación de Orihuela, o lo que es lo mismo el Sur valenciano, y sus conexiones con Murcia. Además, nos facilita la comprensión de los repertorios ornamentales que se emplean luego en retablos, rejerías o en fachadas de cantería, y nos permite definir claramente el estilo, así como las conexiones con otros escultores, como ha sido en este caso con la obra del escultor José Ganga Ripoll.

\section{NOTAS}

\footnotetext{
${ }^{1}$ DEL BAÑO MARTÍNEZ, Francisca, "Las sacristías catedralicias como ámbitos inmaculistas del Barroco", $L a$ Inmaculada Concepción en España: religiosidad, historia y arte: actas del simposium, 1/4-IX-2005 / coordinado por Francisco Javier Campos y Fernández de Sevilla, Vol. 2, 2005, pp. 1127-1146.

2 A partir del concilio de Trento, se generalizó el uso de metales preciosos para confeccionar todo tipo de instrumentos de uso litúrgico, significativamente en plata, y en menor medida en oro.
} 
${ }^{3}$ Entre la amplia bibliografía específica sobre este tema destacamos los trabajos de PUEYO COLOMINA, Ma. Pilar, Las Visitas Pastorales: metodología para su explotación científica en Metodología de la investigación científica sobre fuentes aragonesas, VIII. Zaragoza 1993, pp. 215-268; Las visitas pastorales como fuente para el estudio de la religiosidad popular: el nivel de instrucción en la diócesis de Zaragoza a mediados del s. XVIII, en V Jornadas sobre el estado actual de los estudios sobre Aragón, Zaragoza 1984, pp. 621-623; ANDREU ANDREU, Antonio, La Visita pastoral como instrumentum laboris en la cura animarum de la diócesis de Cartagena, Murcia 1998, p. 6. Son imprescindibles los trabajos recogidos en Memoria ecclesiae, vols. XIV y $\mathrm{XV}$, La visita pastoral en el ministerio del obispo y archivos de la Iglesia, Oviedo 1999. Más recientes, destaca el artículo de GARCÍA HOURCADE, José Jesús; IRIGOYEN LÓPEZ, Antonio, "Las visitas pastorales, una fuente fundamental para la historia de Iglesia en la Edad Moderna", Anuario de Historia de la Iglesia, 2006, sin mes, pp. 293-301.

${ }^{4}$ Como señala Del Baño Martínez en los informes se debía indicar si en su iglesia Catedral había "sacristía suficientemente adornada de lo que es menester para el culto divino y también para celebrar pontificalmente." DEL BAÑO MARTÍNEZ, Francisca, Estancias de uso y representación al servicio de las catedrales españolas durante el barroco, tesis doctoral, Departamento de Historia del Arte, Facultad de Letras, Universidad de Murcia, p. 38.

${ }^{5}$ DEL BAÑO MARTÍNEZ, Francisca, Estancias de uso y representación al servicio de las catedrales españolas durante el barroco, tesis doctoral, Departamento de Historia del Arte, Facultad de Letras, Universidad de Murcia, p. 250.

${ }^{6}$ Sobre esta sacristía véase: GUTIÉRREZ-CORTINES CORRAL, Cristina, Renacimiento y Arquitectura Religiosa en la Antigua Diócesis de Cartagena, Murcia, 1987, pp. 266 y ss.; ID., "Ciudad y Arquitectura en el siglo XVI", en La luz de las Imágenes, Valencia, 2003, pp. 95-151

${ }^{7}$ NIETO FERNÁNDEZ, Agustín, Orihuela en sus documentos, Tomo I, Publicaciones del Instituto Teológico Franciscano, Murcia, 1984, p. 102.

${ }^{8}$ A. D. O. Fondo Archivo Catedralicio de Orihuela. Juntas de parroquia (1730 - 1740). Sig.: 1069. s. f.

${ }^{9}$ Ibídem.

${ }^{10}$ Como indica De la Peña Velasco el tallista y escultor oriolano Antonio Perales era hijo de Bartolomé Perales y hermano de Jacinto. Trabajó con Juan Bautista Borja y realizó obras tan destacadas como la portada de la Capilla de la Comunión de Santiago en Orihuela y su retablo (1733), así como algunos encargos en la vecina población de Cartagena. DE LA PEÑA VELASCO, Concepción, El retablo barroco en la antigua diócesis de Cartagena 1670 - 1758, Departamento de Historia del Arte de la Universidad de Murcia, Murcia, 1992, p. 510.

${ }^{11}$ Ibídem.

${ }^{12}$ Archivo Histórico de Orihuela (en adelante A. H. O). Registros notariales de Julián Risueño, 1732.

${ }^{13}$ Esto parece indicarnos que los diseños no fueron elaborados por Joseph Ganga sino por otro artífice.

${ }^{14}$ Ibídem.

${ }^{15}$ La vinculación de este carpintero con la parroquia de El Salvador era muy acusada como queda reflejada en la junta parroquial del 24 de junio de 1737, dónde Ginés Martínez solicitó a los parroquianos que tras haber servido a la parroquia durante catorce años se le nombrase maestro parroquiano con el objeto de realizar los trabajos menudos que no necesitaban remate. La parroquia accedió a la propuesta y fue elegido como maestro parroquiano asegurándose por tanto los trabajos de menor envergadura. A. D. O. Fondo Archivo Catedralicio de Orihuela. Juntas de parroquia (1730 - 1740). Sig.: 1069. s. f.

${ }^{16}$ En esta ocasión referido como Maestro tallista.

${ }^{17}$ A. D. O. Fondo Archivo Catedralicio de Orihuela. Juntas de parroquia (1730 - 1740). Sig.: 1069. s. f.

${ }^{18}$ Ibídem.

${ }^{19}$ Ibídem.

${ }^{20}$ En esta junta de nuevo se le denomina como maestro escultor.

${ }^{21}$ De esta forma se daba cumplimento al capítulo 22 de la obra en donde se especificaba la obligatoriedad de nombrar maestros veedores que reconocieran la obra.

${ }^{22}$ NIETO FERNÁNDEZ, Agustín, Orihuela en sus documentos, Tomo I, Publicaciones del Instituto Teológico Franciscano, Murcia. 1984, p. 104.

${ }^{23}$ Ibídem, p. $104-105$. 
${ }^{24}$ BELDA NAVARRO, Cristóbal, Estudios sobre Francisco Salzillo, servicio de publicaciones, Universidad de Murcia, 2015, pp. $87-88$.

${ }^{25}$ GONZÁLEZ MORENO, José, Vida y obra de Francisco Salzillo, Universidad de Murcia, Seminario de Historia y Arte, 1945, p. 93.

${ }^{26}$ DE LA PEÑA VELASCO, Concepción, El retablo barroco en la antigua diócesis de Cartagena 1670 - 1758, Departamento de Historia del Arte de la Universidad de Murcia, Murcia, 1992, p. 510.

27 "En treinta de Enero de 1697 bautice a Jusepe, Juan, Bartholomé, hijo de Juan Ganga y de Justa Ripoll, conguges, compadres Juan Beltrán y Vitoriana López, conguges: Nacio a 27 de los dichos. M. Rdo. Joseph Maestre. Cura." Archivo de la Parroquia de El Salvador. Libro de Bautismos 8. 1682 - 1703. Sig.: 13. f. 300.

${ }^{28}$ A. D. O. Fondo Archivo parroquial de las Santas Justa y Rufina de Orihuela, libro de matrimonios, $\mathrm{n}^{\circ} 3$, f. 58 r. Sig.: 47.

${ }^{29}$ En 1697, el cabildo catedralicio de Orihuela pagó a "Juan Ganga fuster de la present ciutat de Oriola, vehy e habitador..." por los trabajos de carpintería de la nueva bodega y granero del Cabildo Catedralicio en la universidad de Almoradí y también por varias obras en la heredad del Aseit y en la Heredad del Rayguer. A. D. O. Fondo Archivo Catedralicio de Orihuela. Registros notariales de Andrés Ximénez, 1697. Sig.: 767 a. F. 558 r - 562 -r. En 1698, el canónigo Aguado le pagó dos barriles de nogal para la citada bodega y granero del Cabildo Catedralicio en la universidad de Almoradí. A. D. O. Fondo Archivo Catedralicio de Orihuela. Registros notariales de Andrés Ximénez, 1698. F. 266 -r. Sig.: 767 b.

${ }^{30}$ Se le pagaron 10 libras por el guardapolvo de madera de la capilla. NIETO FERNÁNDEZ, Agustín, Orihuela en sus documentos, tomo I, p. 80.

${ }^{31}$ El Conde la Viñeza recoge la afirmación de la madre de Salzillo en referencia a su posible salida a Roma para formarse como escultor: “¿Para qué ir tan lejos, cuando aquí cerca, en Orihuela y Alicante, está Juan Bautista Borja llenando de adornos y floripondios, al gusto del día, los retablos y sillerías corales?". VIÑAZA, CONDE DE LA. Adiciones al Diccionario histórico de los más ilustres Profesores de las Bellas Artes en España de D. Juan Agustín Ceán Bermúdez, Madrid, 1884. T. III, p. 339. Citado en BELDA NAVARRO, C. Estudios sobre Francisco Salzillo, Universidad de Murcia, servicio de publicaciones, 2015.

${ }^{32}$ A. D. O. Fondo Archivo parroquial de las Santas Justa y Rufina de Orihuela, libro de matrimonios, $\mathrm{n}^{\circ} 3$, f. 58 r. Sig.: 47.

${ }^{33}$ GONZÁLEZ MORENO, J. Vida y obra de Francisco Salzillo, p. 93.

${ }^{34}$ BELDA NAVARRO, Cristóbal. HERNÁNDEZ ALBADALEJO, Elías, Arte en la Región de Murcia. De la Reconquista a la Ilustración, monografías regionales, Editora Regional de Murcia, Murcia, 2006, p. 404.

${ }^{35}$ SEGADO BRAVO, Pedro, "El retablo de la Capilla del Rosario de Lorca, obra de José Ganga", Imafronte, 34-5, Murcia, 1987-1989, pp. 401-413.

${ }^{36}$ A. H. O. Registros notariales de Julián Risueño.

37 SAEZ VIDAL, Joaquín, Retablos y Retablistas barrocos de Orihuela, Diputación Provincial de Alicante, 1998.

${ }^{38}$ Este edificio ha sido erróneamente considerado como una casa de la nobleza local, en concreto a la familia Enríquez de Navarra (Sánchez Mateos, M $\mathrm{M}^{\mathrm{a}}$ del Carmen. Diz Ardid, Emilio, Orihuela. Guía de monumentos y museos, Asociación Li. Pa. Vega, Orihuela, 2003, p. 101). En realidad esta vivienda perteneció a la élite religiosa local, tal como queda reflejado en las cruces talladas de los cuarterones de sus ventanas, similares a las de la sacristía y aula capitular de la Catedral por citar algún ejemplo similar. Fue erigida por el presbítero beneficiado y residente de la S. I. Catedral el Dr. Cristóbal Rocamora Veliz y puede ser considerada como el modelo de casa de la élite eclesiástica en el Barroco.

${ }^{39}$ A. H. O. Registros notariales de Julián Risueño.

${ }^{40}$ Según indica Concepción de la Peña Velasco, con la denominación de madera salgareña se hacía referencia al Pinus Nigra, conocido en la Sierra del Segura como salgareño, siendo una especie de pino muy antigua, el pino laricio. Señala la autora que la madera de Pino salgareño era muy abundante en el Reino de Murcia como especie preeminente en sus bosques y de muy buena calidad, utilizada en este siglo para la construcción de retablos.

${ }^{41}$ A. D. O. Fondo Archivo Catedralicio de Orihuela. Juntas de parroquia (1730 - 1740). Sig.: 1069. s. f.

${ }^{42}$ Ibídem.

${ }^{43}$ Bernardo Gil Alcaina de oficio platero nació en Orihuela y forjó su oficio en el taller del platero palermitano Antonio Martínez Rubio, situado en la calle de la Feria núcleo de la platería oriolana durante el setecientos, 
durante cuatro años que duró su aprendizaje, poco después instaló su propio taller en la misma calle. RUIZ ÁNGEL, Gemma, CECILIA ESPINOSA. Mariano, "El Arte de la Platería en la Iglesia Parroquial de las Santas Justa y Rufina de Orihuela", Estudios de Platería, San Eloy, Universidad de Murcia, pp. 111 - 128.

${ }^{44}$ A. D. O. Fondo Archivo Catedralicio de Orihuela. Juntas de parroquia (1730 - 1740). Sig.: 1069. s. f.

${ }^{45}$ En este armario se conservan dos bustos de plata con las reliquias de Santa Severa y Santa Florinda, tres bustos de cobre dorado al fuego de San Esteban de Cerdeña, San Esteban protomártir y San Antero con sus respectivas reliquias. Este último relicario ha sido adscrito erróneamente por diversos autores como de san Ceferino. Destacaban entre todas las reliquias un busto de San Pedro con la reliquia de la cruz de su martirio, obra de los plateros platero Miguel de Vera y del genovés Hércules Gargano, así como el Lignum Crucis gótico donado por el obispo de Tarazona, el oriolano Andrés Martínez.

${ }^{46}$ A. D. O. Fondo Archivo Catedralicio de Orihuela. Juntas de parroquia (1730 - 1740). Sig.: 1069. s. f.

${ }^{47}$ Ibídem.

${ }^{48}$ Ibídem.

${ }^{49}$ Ibídem.

${ }^{50}$ Anteriormente, el empleo de la rocalla como motivo decorativo sigue una evolución paulatina que arranca durante la Regencia de Felipe de Orleans $(1715$ - 1722) con la presencia de adornos rocallescos en las decoraciones eventuales y en la orfebrería, y tímidamente en la decoración interior. Los decorados parisinos (1727-1728) difunden ampliamente el nuevo motivo ornamental que definirá la etapa denominada rococó y que adquirirá tintes internacionales con su generalización a través de estampas (1735) y su adopción en toda Europa a lo largo de la década de 1730 (rococó internacional).

${ }^{51}$ A. D. O. Fondo Archivo Catedralicio de Orihuela. Juntas de parroquia (1730-1740). Sig.: 1069. s. f.

Fecha de recepción: 13-10-2017

Fecha de revisión: 09-11-2017

Fecha de aceptación: 11-12-2017 